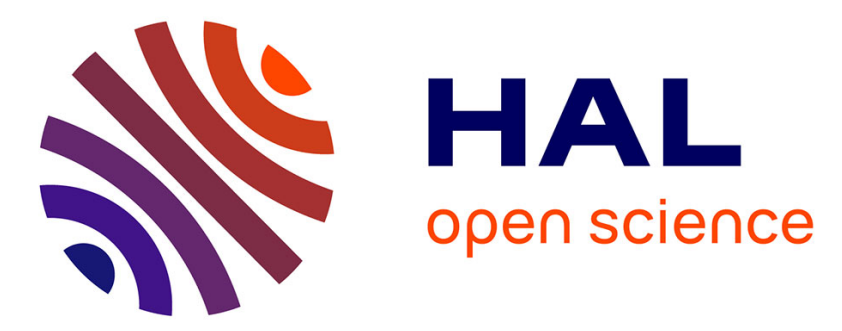

\title{
Cooperative group, risk-taking and inclusion of pupils with learning disabilities in physical education
}

\author{
Amaël André, Benoit Louvet, Pascale Deneuve
}

\section{To cite this version:}

Amaël André, Benoit Louvet, Pascale Deneuve. Cooperative group, risk-taking and inclusion of pupils with learning disabilities in physical education. British Educational Research Journal, 2013, 39 (4), pp.677-693. 10.1080/01411926.2012.674102 . hal-02139657

\section{HAL Id: hal-02139657}

\section{https://hal-normandie-univ.archives-ouvertes.fr/hal-02139657}

Submitted on 3 Jun 2019

HAL is a multi-disciplinary open access archive for the deposit and dissemination of scientific research documents, whether they are published or not. The documents may come from teaching and research institutions in France or abroad, or from public or private research centers.
L'archive ouverte pluridisciplinaire HAL, est destinée au dépôt et à la diffusion de documents scientifiques de niveau recherche, publiés ou non, émanant des établissements d'enseignement et de recherche français ou étrangers, des laboratoires publics ou privés. 


\title{
Cooperative group, risk-taking and inclusion of pupils with learning disabilities in physical education
}

\author{
Amael André $^{\mathrm{a} \star}$, Benoit Louvet ${ }^{\mathrm{b}}$ and Pascale Deneuve ${ }^{\mathrm{b}}$ \\ ${ }^{a}$ University of Rouen, Laboratoire CIVIIC (EA 2657), France; ${ }^{b}$ University of Rouen, \\ Laboratoire CETAPS (EA 3832), France
}

\begin{abstract}
The aim of this research was to study the impact of cooperative learning on changes in cooperative behaviours and acceptance amongst pupils with learning disabilities related to risk-taking. One hundred and sixty-eight French first year middle school pupils participated in this study. Thirty-six pupils with learning disabilities were mainstreamed in six ordinary classes during seven two-hour gymnastic lessons. Three classes practised under low risk conditions and three classes performed under high risk conditions. The helping behaviours of the SEGPA pupils were observed and the acceptance of pupils was measured thanks to a sociometric questionnaire during the first and last lessons. The results showed that risk-taking affected the helping behaviours and the acceptance of pupils with learning disabilities. These results lead us to think about the factors that could have an impact on the influence of cooperative learning structures when mainstreaming pupils with learning disabilities in physical education.
\end{abstract}

Keywords: risk-taking; cooperative learning; peer acceptance; interaction

\section{Introduction}

In French middle schools, pupils with learning disabilities are grouped together in special classes called SEGPA (i.e., Section d'Enseignement Générale et Professionnelle Adaptée/special classes for general and vocational education). According to Sabornie et al.'s (2006) classification, SEGPA students are considered pupils with learning disabilities because of their very poor writing and reading performance. Pupils are placed in these special classes through a formal placement process. The decision of this placement is made by the French Education Department and is based on two criteria. First, the opinion of the teachers about

\footnotetext{
*Corresponding author. Université de Rouen, IUFM de Haute Normandie, 11 rue du Tronquet, 76821 Mont-Saint-Aignan cedex, France. Email: amael.andre@orange.fr
} 
the mastery of the students' academic skills is taken into account. Second, the results obtained by these students in psychometric tests organized by an educational psychologist guide the decision. The guidelines of the French Education Department (2002) encourage the mainstreaming of SEGPA pupils in ordinary PE (i.e., physical education) classes because this discipline does not primarily require intellectual resources which lie at the heart of their difficulties. The aim of this educational policy is to develop positive social relationships between all the pupils. Nonetheless, mainstreaming pupils with learning disabilities in PE does not always appear to be a sufficient condition in order to achieve this goal (Garel, 2001). That is the reason why, beyond mainstreaming, the inclusion of these pupils still needs to be sought.

Indeed inclusion goes beyond simply physically placing a child in a general education classroom (Stainback \& Stainback, 1990). Within the context of inclusion, the focus is on the positive social relationships between pupils with special educational needs and general education pupils (Amstrong, 2001). On the one hand, these relationships provide social roles through the participation of mainstreamed pupils which encourage cooperative interactions between general education pupils and pupils with special educational needs. On the other hand, it encourages acceptance by their peers (Schwartz et al., 2006). Peer acceptance is the degree to which a person is liked or accepted by members of his or her peer group (Bukowski \& Hoza, 1989). More precisely, in the domain of the inclusion of pupils with learning disabilities, acceptance is characterised by two dimensions: peer preference defined by the fact of being liked or rejected by one's peers, and peer impact defined by the fact of being noticed by one's peers (Frederickson \& Furnham, 1998). With this in mind, the question is raised as to the conditions which allow an increase in the cooperative interaction and acceptance of these SEGPA pupils in PE.

Cooperative learning procedures would appear to be an interesting avenue to explore. Many studies have pointed out the impact of cooperative learning in intellectual tasks on the relationships between general education pupils and pupils from special education programmes (Johnson et al., 1983). Cooperative learning is an instructional format in which pupils work together in small, structured, heterogeneous groups to master the content of the lesson (Putnam, 1998). Studies have indicated that cooperative learning positively affected the acceptance of pupils with physical or mental handicaps (Lloyd, Crowley, Kohler, \& Strain, 1988; Margolis et al., 1991). It has also been demonstrated that it promotes positive interaction between pupils with learning disabilities and general education pupils (Gillies \& Ashman, 2000; Putnam et al., 1989). Some research has indicated that cooperative learning techniques yielded significant increases in the peer acceptance of pupils with learning disabilities by general education pupils as opposed to individual learning (Jacques et al., 1998; Piercy et al., 2002).

Five main elements are recommended to implement a cooperative learning structure (Johnson \& Johnson, 1989): face-to-face interaction, positive interdependence, individual accountability, interpersonal and small group skills and group processing. Face-to-face interaction is effective when small groups are created and 
the group members are working on a task in close proximity to one another. Positive interdependence is achieved when group members learn to depend on the rest of the group while working together to complete the task. According to Johnson and Johnson (2000) positive interdependence is a key element in cooperative learning structures because it promotes positive relationships between different pupils at school. For the authors, positive interdependence is strongest when pupils have complementary roles within a small group to successfully carry out a common task. The third element, individual accountability, refers to pupils taking responsibility for completing their part of the task for their group. Interpersonal and small group skills such as helping, shared decision-making and taking responsibility, make up the fourth element. They are developed through tasks in which pupils work together. This aspect of a cooperative learning structure is of great importance because it entails behavioural interactions whose degree of execution reflects the engagement of the pupils and the attainment of positive social relationships among the class. The last element, group processing, is a debriefing after the learning task. It is the time allocated to discussing how well group members are achieving their goals and maintaining effective working relationships.

In the PE and sports domain, Lafont and Winnykamen (1999) have distinguished three levels of cooperation. The first level is reached when group members share a common goal. The second level is characterised by coordination of actions of the group members in order to attain the goal. The last level is cooperative learning. It is reached when individuals help their teammates to learn through social roles. Several studies have been carried out on the impact of cooperative learning on peer relationships in PE. Johnson (1984) indicated the positive effects of cooperative learning on attitudes towards the class in golf as opposed to individual learning. Cooperative learning structures in physical education can develop social interaction of pre-school children (Grineski, 1989) and primary school children (Grineski, 1993). Dyson (2002) showed cooperative learning encouraged greater peer support and positive pupil-to-pupil interaction in volleyball and basketball units with pupils aged eight to nine. In this study, pupils were responsible for taking different roles. The results stressed the importance of taking various roles in small groups. Mascret (2009) showed the importance of creating a positive interdependence between pupils in an individual sport thanks to a common result. Adding the coach's and the player's results enabled an increase in social skills for failing first year French pupils in a cooperative dyad work in badminton. However, there has not been any study which deals with the influence of cooperative learning structures in PE on the interaction and the acceptance of mainstreamed pupils with learning disabilities.

Cousin (2003) indicated a deficit in social skills amongst the characteristics of SEGPA pupils. According to this author, these difficulties make it hard work in small groups with these pupils. As Mascret (2009) showed, pupils with academic difficulties only invest in cooperative roles that they value. Moreover, SEGPA pupils are heavily stigmatised and rejected by the other pupils in French middle schools because they belong to special needs classes within the same school (Pasquier, 1999). A study by Ninot and Maiano (2007) found no effect of the type 
of athletic programme (integrated versus segregated) in swimming and basketball on the perceived acceptance of mainstreamed SEGPA pupils. Putnam et al. (1996) pointed out that, as well as during intellectual tasks, the degree of acceptance of special needs pupils among 11- to 15-year-olds mainstreamed in ordinary classes has been stable despite the cooperative structures put in place. According to Michinov (2001), the sharing of common values during adolescence is an important factor in interpersonal relationships. Over and above cooperation, it is important to consider the values that can be shared by both classes. Consequently, this study focuses on one of these important values: risk-taking.

Indeed risk-taking is an important value for pre-teenagers and teenagers (Le Breton, 2002). It occupies an important position in their interpersonal relationships (Lightfoot, 1997) and can also have an influence on their popularity (Assailly, 1992). Risk-taking is characterised by engagement in situations where there is something at stake and a degree of uncertainty about the outcome (Hans, 1984). In sport, Delignières (1993) identified two types of important risk-taking. Firstly, social risk-taking is linked to the risk of being socially devalued. Secondly, physical risk-taking is characterised by the risk of physical injury. As far as the second type of risk-taking is concerned, the author makes the distinction between objective risk-taking characterized by a real threat of injury, and what is perceived as subjective risk-taking. Physical risk-taking is an important factor in French teenagers' engagement in sports activities (Recours et al., 2004). This form of risktaking provokes strong emotions (Zuckerman, 1990) and has a bonding effect on peer groups in sports (Soulé \& Corneloup, 2006).

Gymnastics appears to be an activity where the risk of physical injury could be high (Eisenbeis \& Touchard, 1995). However, the perceived risk is linked to height in executing a particular exercise (Delignières, 1991). In gymnastics, Durand (1987) showed that the same exercise was perceived by the pupils as being riskier the higher the apparatus. Two types of school gymnastics have been identified (Goirand, 1994). Acrobatic gymnastic risk-taking based on higher and higher airborne exercises within an adapted space, and a more technical and traditional gymnastics centred on a series of basic exercises broken down into shorter sequences and thereby reducing the level of risk-taking. In accordance with relevant curricular guidance, acrobatic gymnastics, in which the scoring system focuses on mastering risky acrobatics is preferred to traditional gymnastics for middle school pupils, particularly those with academic difficulties (Duboz et al., 2000; Duboz, 2001).

Concerning the mainstreaming of pupils with learning disabilities in PE, Deneuve et al. (2002) pointed out the role played by risk-taking and its effect on the acceptance of these pupils by the others. The results showed that participation in acrobatic gymnastic activities led to an increase in acceptance of pupils with learning disabilities. However, this study was carried out uniquely on individual practice and not within the framework of cooperative learning structures.

This research dealt with the impact of risk-taking in gymnastics on the helping behaviours and acceptance of SEGPA pupils within a framework of cooperative learning structures. 


\section{Method}

A quasi-experimental design was adopted in a real educational setting.

\section{Participants}

One hundred and sixty-eight pupils from French first year middle schools (aged between 11 and 12) participated in the experiment. One hundred and thirty-two pupils (69 boys and 63 girls) belonged to six ordinary classes and the 36 others (26 boys and 10 girls) were part of three SEGPA classes. The ordinary classes are comprised of children from working-class backgrounds with an average academic level. The SEGPA pupils are from poor and working-class families and are punctually mainstreamed in ordinary classes selected for this study in music, technology and PE. The selected SEGPA and ordinary pupils did not have any specific experience in gymnastics.

\section{Procedure}

A cooperative learning structure was implemented in gymnastics. The five elements stressed by Johnson and Johnson (1989) have been taken into consideration.

First, SEGPA pupils were integrated individually into teams of three. The positioning of teams in different sections of the gymnasium encouraged face-to-face interaction. Second, positive interdependence was favoured. On the one hand, within each team, complementary roles were assigned (Dyson, 2002). A team was composed of one gymnast and two helpers/finishers. After three attempts, the pupils were asked to swap roles. On the other hand, the result was a team effort based on the addition of each team member's score (Mascret, 2009). Third, each team member was individually accountable because he or she had a role to play and the results were taken into account in the team's result. Fourthly, interpersonal skills were required for helpers/finishers. The helpers/finishers had to help the gymnast to successfully complete the movement according to the execution criteria (amplitude, posture, maintaining balance) and to prevent him or her from falling. Then they had to position themselves and place their hands on the gymnast (generally on the shoulders and the hips). Helpers/finishers' actions are a major concern because they breed specific interpersonal skills that can potentially determine the future degree of inclusion of the pupils. Finally, during a debriefing period of five minutes at the end of the class, the teacher led an evaluation discussion on the group activities and results and stressed the importance of helping each other.

The three levels of cooperation identified by Lafont and Winnykamen (1999) exist in this experiment. The first level is present because teammates share a common goal through a common score. The second level is present because the gymnast and the helpers/finishers have to coordinate their actions to attain the goal. The last level is reached because the helpers/finishers help the gymnast to learn. Indeed they facilitate the engagement of the gymnast in the learning tasks which can be perceived as risky. Moreover they have to help the gymnasts to experiment with the feelings linked to 
the amplitude and the postures required to succeed. As noted by Goirand (1994) as regards gymnastics, assisting beginners allows them to feel the right movements.

\section{Lesson content}

Eight gymnastic tasks were proposed to the pupils. These tasks were grouped together by gymnastic themes which encourage rotations and somersaults (in accordance with the French PE programme): a forward rotation, a backward rotation, a forward somersault from a run and jump, a handstand, a cartwheel, a headstand, a jump on a beam, and a loop on a horizontal bar. A scoring system was established for each exercise with a hierarchy of three different degrees of difficulty associated with three criteria of execution (amplitude, balance and posture).

In three classes ('risk group') the pupils were encouraged to go higher and higher. The degree of difficulty was based on the risk taken through the height of execution of the exercises and the flight achieved (Duboz et al., 2000). In the three other classes ('control group') the pupils had to repeatedly execute more and more technically demanding exercises but always at the same height. The scoring system was based on a finer and finer breaking down and combination of simple movements.

\section{Organization device}

Six SEGPA pupils were mainstreamed in each of the ordinary classes. This type of mainstreaming is the usual practice in French middle schools (Garel, 2001). The six classes participated in seven two-hour lessons over a six-week period (corresponding to the official PE timetable in the French programme). In the first lesson, all the gymnastic exercises undertaken by the pupils in the six classes were identical. In the six following lessons, three classes were encouraged to carry out exercises that were increasingly airborne ('risk group') while the three other classes were encouraged to multiply a string of increasingly technical exercises but always at the same height ('control group').

\section{Instruments}

In both groups, the data were collected during the first lesson (which is the pre-test) and then during the seventh lesson (which is the post-test).

Observation of helping behaviours. The helping behaviours of each SEGPA pupil as a helper/finisher were filmed in two exercises: a handstand and a backward rotation roll. The helping behaviours are included in the fourth element building up a cooperative learning structure (i.e., interpersonal skills). These exercises were chosen as their execution is often slow and they facilitate support and help. Each SEGPA pupil was filmed for 16 minutes (eight minutes per exercise). The behavioural interactions of the SEGPA pupils were classified by two gymnastics experts into two categories: presence of an efficient help and absence of an efficient helper. 
- Presence of an efficient helper: This category included the helping behaviours of SEGPA pupils which respect the criteria for success of this help during the gymnast's performance. First the helper had to stand next to the gymnast. Second, manual contact from the helper/finisher on the right part of the gymnast's body (shoulders and hips) had to be present during the execution of the exercise.

- Absence of an efficient helper: This category grouped all the other behaviours of SEGPA pupils during the gymnastic exercise of their teammates.

The inter-observer agreement was very good for the presence of an efficient helper $(k=.94)$ and also for the absence of an efficient helper $(k=.94)$.

Sociometric questionnaire. The sociometric rating scale techniques (Oden \& Asher, 1977) were used to assess peer acceptance of SEGPA pupils. The sociometric rating method is suitable for measuring acceptance (Maassen et al., 2000). According to Frederickson and Furnham (1998), the use of the rating method has several advantages. It collects much information enabling broader pictures of social groups and overall acceptance levels to emerge. Moreover, it is more acceptable at school than negative nomination practices.

The procedure employed by Frederickson and Furnham (1998) was adapted for this PE setting to assess peer acceptance indices of mainstreamed pupils with learning disabilities. In each mainstream class, pupils were presented with a complete list of the names of all pupils and given the following question. How much would you like to practise sport with...? Only one question was asked because of the high levels of concentration disruption encountered by SEGPA pupils in an intellectual task. The pupils were given four alternatives. The first was a smiley face indicating they would have liked to do sports with this pupil. The second was a neutral face indicating they did not mind doing sports with this pupil. The third was a sad face indicating they would not have liked to do sports with him or her. The last alternative was a question mark enabling the pupils to express that they did not know him or her enough to give an answer. The pupils had to circle one of the four symbols for each of the other pupils. The peer preference score of each pupil was calculated as follows: number of smiley faces received minus number of sad faces received. A preference index was computed by dividing the peer preference score received by the total number of pupils who answered. The peer impact score was calculated as follows: number of smiley faces received plus number of sad faces. The peer impact index was then computed by dividing this score by the total number of pupils who answered.

Two other classes mainstreaming pupils with learning disabilities were used to assess reliability. The measurements were administered seven weeks apart without mainstreaming in PE, the correlations between the pre-test and post-test yield a coefficient of 0.86 for the peer preference index and a coefficient of 0.88 for the peer impact index. The sociometric indices were thus temporally stable. 
The usual precautions associated with sociometric tests (e.g., confidentiality, brief and clear questions) were taken (Parlebas, 1992).

\section{Analysis}

Group (risk/control) by time (pre-test/post-test) ANOVAs with a repeated measurement on the last dimension were undertaken on each of the dependant variable measurements (i.e., categories of helping behaviours and sociometric indices) to analyse the impact of risk-taking on the change of helping behaviours and acceptance of SEGPA pupils.

\section{Results}

Analysis of SEGPA pupils' helping behaviours

The means and standard deviations of SEGPA pupils' helping behaviour in both groups in the pre-test and post-test are presented in Table 1. A group (risk/control) by time (pre-test/post-test) ANOVAs with a repeated measure on the last dimension were carried out to measure the change in each category of the helping behaviours of the SEGPA pupils according to the group.

Presence of an efficient helper. A significant group $\mathrm{x}$ time interaction effect was found on the number of the 'presence of an efficient helper' amongst SEGPA pupils, $F(1,34)=14.14, p<.001, \eta_{\mathrm{p}} 2=.29$. The treatment group applied during the time of the experimentation influenced significantly the number of the 'presence of an efficient helper' amonst SEGPA pupils. Subsequent analyses of effects of group using t-test revealed no significant difference between the two groups $\left(M_{\text {control }}=\right.$ 9.0, $\left.S D=5.16 ; M_{\text {risk }}=8.39, S D=6.06\right)$ during the pre-test, $t(34)=-0.33$, $p>.05$. At the post-test, the number of efficient helps differed significantly between the two groups, $t(34)=2.63, p<.01, r=.41$. Indeed, the number of efficient helps increased significantly, $t(17)=-2.36, \mathrm{p}<.05, \mathrm{r}=.50$, for the SEGPA

Table 1. Means and standard deviations of helping behaviours of SEGPA pupils by treatment group and time

\begin{tabular}{|c|c|c|c|c|}
\hline \multirow[b]{3}{*}{ Variable/time } & \multicolumn{4}{|c|}{ Group } \\
\hline & \multicolumn{2}{|c|}{ Risk } & \multicolumn{2}{|c|}{ Control } \\
\hline & $M$ & $S D$ & $M$ & $S D$ \\
\hline \multicolumn{5}{|l|}{ Efficient help } \\
\hline Pre-test & 8.39 & 6.06 & 9.00 & 5.16 \\
\hline Post-test & 11.72 & 7.12 & 5.83 & 6.26 \\
\hline \multicolumn{5}{|c|}{ Absence of efficient help } \\
\hline Pre-test & 10.67 & 6.99 & 7.61 & 6.69 \\
\hline Post-test & 10.22 & 7.53 & 16.06 & 9.12 \\
\hline
\end{tabular}


pupils in the risk groups $\left(M_{\text {risk }}=11.72, S D=7.12\right)$ and became significantly higher than those in the control group at post-test $\left(M_{\text {control }}=5.83, S D=6.26\right)$. The latter decreased significantly the number of the 'presence of an efficient helper' during the experimentation, $t(17)=3.16, p<.01, r=.61$. This interaction effect is plotted in Figure 1.

Absence of an efficient helper. The results showed a significant group by time interaction effect, $F(1.34)=6,05, p<.05, \eta_{\mathrm{p}} 2=.15$. The treatment group applied during the time of the experimentation affected significantly the absence of efficient help of SEGPA pupils. Subsequent analyses of effects of group using t-test revealed no significant difference between the two groups $\left(M_{\text {control }}=7.61, S D=\right.$ $\left.6.69 ; M_{\text {risk }}=10.67, S D=6.99\right)$ during the pre-test, $t(34)=1.34, p>.05$, but the difference at the post-test was significant, $t(34)=-2.09, p<.05, r=.34$. Indeed, at the post-test the number of the 'absence of an efficient helper' was less important for the SEGPA pupils in the 'risk group' $\left(M_{\text {risk }}=10.22, S D=7.53\right)$ than in the 'control group' $\left(M_{\text {control }}=16.06, S D=9.12\right)$. The number of the 'absence of an efficient helper' remained stable during the experiment in the 'risk group', $t(17)=0.18, \mathrm{p}>.05$. The number of the 'absence of an efficient helper' increased significantly in the control group, $t(17)=-3.15, \mathrm{p}<.01, \mathrm{r}=.61$. This interaction effect is plotted in Figure 2.

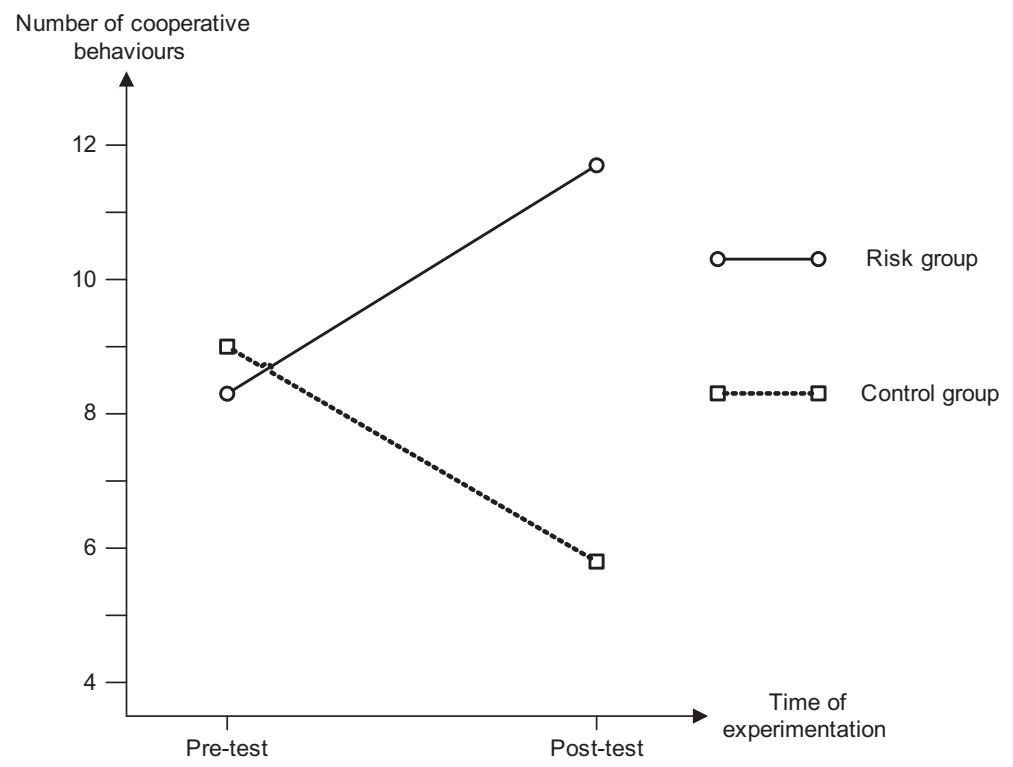

Figure 1. Interaction effect of group (i.e., control/risk) and time of experimentation (i.e., pre-test/post-test) on efficient helps of SEGPA students 




Figure 2. Interaction effect of group (i.e., control/risk) and time of experimentation (i.e., pre-test/post-test) on absence of efficient help

\section{Analysis of the acceptance of SEGPA pupils}

The means and standard deviations of the sociometric indices for pupils in both groups at the pre-test and the post-test are presented in Table 2. An independent $t$-test conducted on the preference indices confirmed that SEGPA students $(M S E G P A=-0.27, \mathrm{SD}=0.17)$ were significantly less preferred than their regular counterparts $\left(\mathrm{M}_{\text {regular }}=0.15, \mathrm{SD}=0.23\right)$ at the beginning of the experimentation, $t(166)=-10.3, p<.001, r=.62$

Group (risk/control) by time (pre-test/post-test) ANOVAs with a repeated measure on the last dimension were carried out to measure the changes in the pupils' sociometric indices according to the group.

Preference indices of SEGPA pupils. The results showed a significant group by time interaction effect, $F(1.34)=5.13, p<.05, \eta_{\mathrm{p}} 2=.13$. The treatment group applied during the time of the experimentation influenced significantly the preference indices received by the SEGPA pupils. Subsequent analyses using paired $t$-test confirmed that the preference indices increased significantly between pre-test $\left(M_{\text {risk }}=-0.25, S D=0.18\right)$ and post-test $\left(M_{\text {risk }}=-0.12, S D=0.24\right)$ for the SEGPA pupils in the 'risk group', $t(17)=-4.67, p<.001, r=.75$, whereas the difference in preference indices between pre-test and post-test for pupils in the 'control group' was not significant, $t(17)=-0.75, p>.05$. The interaction effect is plotted in Figure 3. 
Table 2. Means and standard deviations of sociometric indices by treatment group and time

\begin{tabular}{|c|c|c|c|c|}
\hline \multirow[b]{3}{*}{ Variable/time } & \multicolumn{4}{|c|}{ Group } \\
\hline & \multicolumn{2}{|c|}{ Risk } & \multicolumn{2}{|c|}{ Control } \\
\hline & $M$ & $S D$ & $M$ & $S D$ \\
\hline \multicolumn{5}{|l|}{ PI SEGPA } \\
\hline Pre-test & -0.25 & 0.18 & -0.27 & 0.15 \\
\hline Post-test & -0.12 & 0.24 & -0.25 & 0.19 \\
\hline \multicolumn{5}{|l|}{ II SEGPA } \\
\hline Pre-test & 0.52 & 0.10 & 0.50 & 0.09 \\
\hline Post-test & 0.48 & 0.11 & 0.53 & 0.10 \\
\hline \multicolumn{5}{|l|}{ PI Ordinary } \\
\hline Pre-test & 0.14 & 0.24 & 0.16 & 0.20 \\
\hline Post-test & 0.13 & 0.26 & 0.17 & 0.22 \\
\hline \multicolumn{5}{|l|}{ II Ordinary } \\
\hline Pre-test & 0.49 & 0.12 & 0.50 & 0.11 \\
\hline Post-test & 0.49 & 0.12 & 0.49 & 0.12 \\
\hline
\end{tabular}

Notes: $\mathrm{PI}=$ preference index; $\mathrm{II}=$ impact index.

Impact indices of SEGPA pupils. The ANOVA showed no significant group effect, $F(1.34)=0.44, p>.05$, no time effect, $F(1.34)=0.05, p>.05$ and no group by time interaction effect, $F(1.34)=0.77, p>.05$.

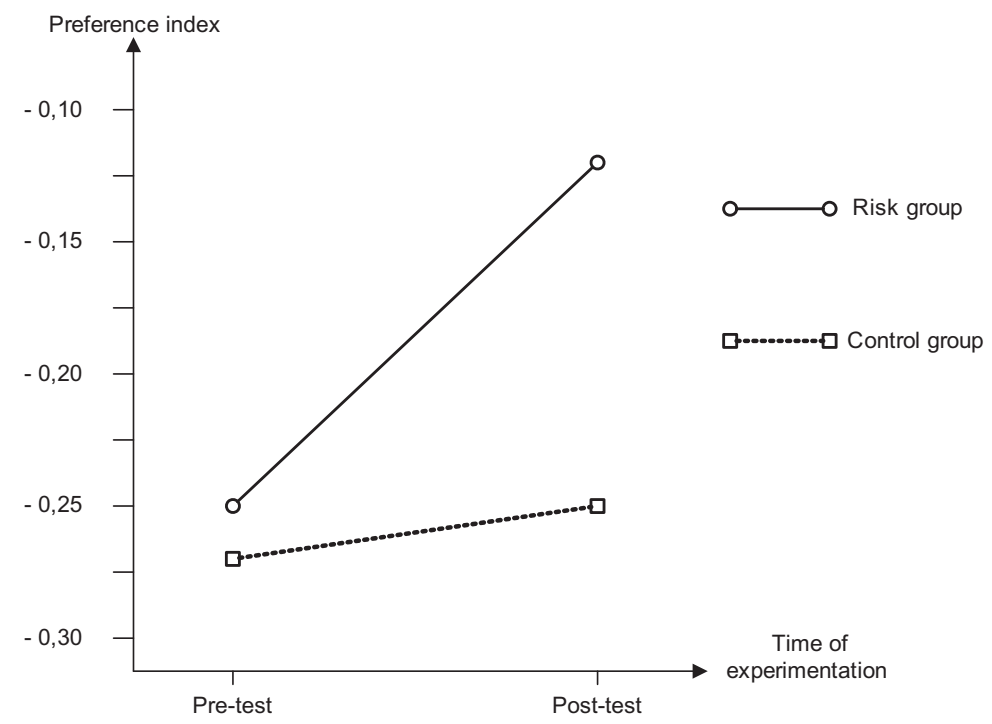

Figure 3. Interaction effect of group (i.e., control/risk) and time of experimentation (i.e., pre-test/post-test) on preference indices of SEGPA students 
Preference indices of ordinary pupils. The results showed no significant group effect, $F(1.130)=0.30, p>.05$, no time effect, $F(1.130)=0.24, p>.05$ and no group by time interaction effect, $F(1.130)=0.13, p>.05$.

Impact indices of ordinary pupils. The ANOVA indicated no significant group effect, $F(1.130)=0.06, p>.05$, no time effect, $F(1.130)=0.41, p>.05$ and no group by time interaction effect, $F(1.130)=0.03, p>.05$.

\section{Links between preference index of SEGPA pupils and helping behaviours}

Results showed that there was an effect of helping behaviours on the preference index of SEGPA pupils who practised in the 'risk group', $F(1.34)=13.87$, $p<.001, \omega=.70$, and in the 'control group', $F(1.34)=9.25, p<.01, \omega=.45$. In the 'risk group' and in the 'control group', the SEGPA pupils who presented more helping behaviours $\left(M_{\text {risk }}=-0.07, S D=0.18 ; M_{\text {control }}=-0.18, S D=0.17\right)$ were more accepted than their counterparts who did not provide helping behaviours $\left(M_{\text {risk }}=-0.31, S D=0.21 ; M_{\text {control }}=-0.33, S D=0.14\right)$.

\section{Discussion}

The aim of this research was to study the impact of risk-taking on the helping behaviours and the acceptance of SEGPA pupils within a framework of cooperative learning.

The results showed that the evolution of helping behaviours of SEGPA pupils was dependent on risk-taking. In the post-test, the number of the 'presence of an efficient helper' was higher in the 'risk group' than in the 'control group'. At the same time the absence of efficient help was more apparent in the 'control group' than in the 'risk group'. The results obtained by Putnam et al. (1991) on the influence of cooperative structures on the interactions between mainstreamed pupils with disabilities and ordinary pupils should be carefully balanced according to the variable degree of risk-taking in gymnastics. This leads us to think that risk-taking linked to the height of execution of an exercise gave a sense to positive interdependence between the helpers/finishers and the gymnast. As Mascret (2009) showed in badminton, it is important to consider the value attributed by the pupils with academic difficulties to cooperative roles in order to provoke cooperative interaction. The role of the helpers/finishers in the 'control group' was above all related to the respect of the criteria for execution such as amplitude, body alignment and maintaining balance. On the other hand, the dimension of risk prevention was noticeably present in the 'risk group'. Indeed, the helpers/finishers were responsible for the physical safety of the gymnast by preventing a fall from a greater height. Furthermore, it can be argued that the helpers/finishers facilitated the engagement of certain gymnasts confronted with a situation perceived as risky. It can be suggested that the coordination of the movements between the helpers/finishers and 
the gymnast was perceived as more useful as the risk was greater. This leads us to think that the execution of certain airborne gymnastic exercises was an opportunity for pupils to share strong emotions provoked by risk-taking (Zuckerman, 1990) and to create a bonding effect (Soulé \& Corneloup, 2006). Risk-taking gave an added value to the cooperative learning tasks executed by the SEGPA pupils in our study. The study was limited to setting up a social driving force role, that of helper/finisher, as we did not want to put the SEGPA pupils in a difficult position by proposing cognitive roles such as judge. Nevertheless, it would be interesting to broaden the research on the impact of risk-taking on other types of interaction such as verbal interactions.

The results of our study showed that the acceptance of the SEGPA pupils in the 'risk group' increased more noticeably than those in the 'control group'. The preference indices increased significantly for pupils in the 'risk group' while in the 'control group' this was not the case. These results confirm those obtained by Deneuve et al. (2002) on the influence of risk-taking on the acceptance of pupils with learning disabilities during individual exercises. This leads us to suppose that executing airborne gymnastic exercises was an opportunity for SEGPA pupils and ordinary pupils to share their common interests and values at an age when risktaking is an important part of the pupils' preferences. Among other things, the SEGPA pupils in the risk group had to prove they were capable of taking risks by executing gymnastic exercises on a raised apparatus. Thus, risk-taking affords popularity among pre-teenagers, and among boys in particular (Assailly, 1992). In our study, the SEGPA pupils were mostly boys, as boys make up the majority of SEGPA pupils in France. It would be interesting in a future study to see if these results could be generalised for a largely female population. It can also be suggested that preference indices of SEGPA pupils are linked with their helping behaviours. Indeed results showed that sociometric indices of SEGPA pupils who have helped their teammates efficiently were higher than those of SEGPA pupils who did not help their teammates efficiently. These results are in line with numerous studies which have found that peer acceptance and social behaviours are strongly linked (e.g., Rubin et al., 1998). Popular children have been found to behave very positively toward peers whereas rejected children had many antisocial behaviours.

In this study, we focused on target effects through the sociometric scores received by SEGPA pupils. In a future research it could be interesting to focus on the sociometric scores not only received by the SEGPA pupils but also on the sociometric scores emitted by their counterparts in order to explore more precisely the relationship between results of cooperative behaviours and peer acceptance. As demonstrated by LaFontana and Cillessen (2002), the possibilities of using Kappa coefficients to compute pairs of peer preference scores emitted by the ordinary pupils toward the SEGPA pupils and cooperative behaviours will be fruitful to further understand the nature of effects of cooperative learning.

If these results showed that the SEGPA pupils acceptance increased in the 'risk group', this was not the case in the 'control group'. These results balance those 
obtained by Piercy et al. (2002) on the influence of cooperative learning structures on the acceptance of pupils with learning disabilities mainstreamed in ordinary classes. It could be said that these results are linked to the structure of French middle schools. Earlier studies focused on primary school children, and yet in French middle schools SEGPA pupils are heavily stigmatised and rejected (Pasquier, 1999). Indeed, the identification of SEGPA pupils appears systematically to refer to the structure to which they belong and the delimited geographic zone they occupy within schools. Furthermore, these middle schools welcome teenagers and preteenagers with a strong sensitivity towards conforming to their peer group (Horn, 2006). Accepting SEGPA pupils burdened with a devalued status could pose a problem for ordinary pupils who themselves risk having their status devalued. The results showed that the sociometric indices of ordinary pupils remain unchanged whatever the treatment put in place. We can suggest that the relational structure within regular classes was stable and the time of the experimentation was not sufficient to change this structure. Our experimentation was carried out over a limited period of time (seven times, two hours) corresponding to the time allotted to PE in the French programme. It would be interesting to continue this study over a longer period covering several academic cycles, to see if the results obtained endure.

This research showed that risk-taking has a positive effect on the influence of cooperative learning structures in gymnastics on the helping behaviours and on the acceptance of SEGPA pupils. Getting SEGPA and ordinary pupils to work in cooperative learning groups is insufficient in obtaining positive effects on the relationships between these pupils. The introduction of cooperative learning structures presenting risk-taking appears to be a promising avenue in favouring the inclusion of SEGPA pupils in PE. These results lead PE teachers to think about the factors that could have an impact on the influence of cooperative learning structures when mainstreaming SEGPA pupils. Sharing common values appears essential in facilitating the inclusion of pupils with disabilities. It is a question of identifying the values that can be shared through the proposed sports and facilitate the inclusion. The mainstreaming of pupils with learning disabilities in PE is a complex phenomenon. More studies in other sports, with other populations, are needed to help physical educators and educators alike to better understand the effect of mainstreaming through physical education.

\section{References}

Armstrong, F. (2001) Intégration ou inclusion? L'évolution de l'éducation spéciale en Angleterre [Integration or inclusion? The evolution of special education in England] Revue française de pédagogie, 134(1), 87-96.

Assailly, J.P. (1992) Les jeunes et le risque [Youth and risk] (Paris, Vigot).

Bukowski, W.M. \& Hoza, B. (1989) Popularity, friendship: Issues in theory, measurement, and outcome, in: T.J. Berndt \& G.W. Ladd (Eds) Peer friendships in child development (San Fancisco, Jossey-Bass), 23-37.

Cousin, C. (2003) Enseigner en SEGPA et EREA [Teach students with learning disabilities from special classes] (Paris, Delagrave). 
Delignières, D. (1991) Risque perçu et apprentissage moteur [Perceived risk and motor learning], in: J.P. Famose, P. Fleurance \& Y. Touchard (Eds) Apprentissage moteur: róle des représentations (Paris, EPS).

Delignières, D. (1993) Risque préférentiel, risque perçu et prise de risque [Preferential risk, perceived risk and risk taking], in: J.P. Famose (Ed.) Cognition et performance (Paris, INSEP).

Deneuve, P., Genty, J. \& Dru, V. (2002) Modification des affinités interpersonnelles intergroupes en fonction du type d'activité partagée et des compétences perçues en milieu scolaire [Changing of interpersonal intergroup affinities according to the kind of shared activities and the perceived competences in an academic environment], Les Cahiers internationaux de Psychologie Sociale, 54(1), 71-76.

Duboz, S. (2001) Ringarde la gym? Pas forcément, Contre-pied, 12(1), 41-43.

Duboz, S., Policarpo, D. \& Héraud, A. (2000) Acro-gym: code de pointage [Acrobatic gymnastic: Scoring system] (Paris, Editions revue EP.S).

Durand, M. (1987) L'enfant et le sport [Child and sport] (Paris, PUF).

Dyson, B. (2002) The implementation of cooperative learning in an elementary physical education program, fournal of Teaching in Physical Education, 22(1), 69-85.

Eisenbeis, J. \& Touchard, Y. (1995) Education à la sécurité [Safety education] (Paris, Editions revue E.PS).

Frederickson, N.L. \& Furnham, A.F. (1998) Sociometric status group classification of mainstreamed children who have moderate learning disabilities: An investigation of personal and environmental factors, Fournal of Educational Psychology, 90(4), 772-783.

Garel, J.P. (2001) L'intégration des élèves de SEGPA en Éducation physique et sportive: entre espoirs et illusions [SEGPAs integration in physical education and sport: Between hopes and illusions], La nouvelle revue de l'AIS, 14(1), 61-71.

Gillies, R.M. \& Ashman, A.F. (2000) The effects of cooperative learning on students with learning difficulties in the lower elementary school, fournal of Special Education, 34(1), $19-27$.

Goirand, P. (1994) Des pratiques sociales en gymnastique aux pratiques scolaires [Social practices in gymnastics and school practices], Spirales, 7(1), 145-149.

Grineski, S. (1989) Children, games and prosocial behaviour, fournal of Physical Education, Recreation and Dance, 60(8), 20-25.

Grineski, S. (1993) Achieving instructional goals in physical education: A missing ingredient, Fournal of Physical Education, Recreation E Dance, 64(5), 32-34.

Hans, D., 1984. La prise de risque. Définition et problèmes posés par l'utilisation de ce concept [Risk-taking, definition and problems about the using of this concept]. STAPS, 9(1), 19-29.

Horn, S.S. (2006) Group status, group bias, and adolescents' reasoning about the treatment of others in school contexts, International fournal of Behavioural Development, 30(3), 208-218.

Jacques, N., Wilton, K. \& Townsend, M. (1998) Cooperative-learning and social acceptance of children with mild intellectual disabilities, fournal of Intellectual Disabilities Research, 42(1), 29-36.

Johnson, D.W. \& Johnson, R.T. (1989) Cooperation and competition: Theory in the research (Edina, MN, Interaction Book CO).

Johnson, D.W. \& Johnson, R.T. (2000) The three Cs of reducing prejudice and discrimination, in: S. Oskamp (Ed.) Reducing prejudice and discrimination (Mahwah, NJ, Lawrence Erlbaum).

Johnson, D.W., Johnson, R. \& Maruyama, G. (1983) Interdependence and interpersonal attraction among heterogeneous and homogeneous individuals: A theoretical formulation and a meta-analysis of the research, Review of Educational Research, 53(1), 5-54. 
Johnson, R.T. (1984) The effects of cooperative, competitive and individualistic student interaction patterns on the achievement and attitudes of students learning the golf skill of putting, Research Quaterly for Exercise and Sport, 55(2), 129-134.

Lafont, L. \& Winnykamen, F. (1999) Co-operation and competition in children and adolescents, in: Y. Vanden Auweele, F. Bakker, M. Durand \& R. Seiler (Eds) Textbook on psychology for physical educators (Champaign, IL, Human Kinetics), 379-404.

LaFontana, K.M. \& Cillessen, A.H.N. (2002) Children's perceptions of popular and unpopular peers: A multimethod assessment, Developmental Psychology, 38, 635-647.

Le Breton, D. (2002) Conduites à risque [Risked behaviours] (Paris, Puf).

Lightfoot, C. (1997) The culture of adolescent risk-taking (New York, The Guildford Press).

Lloyd, J.W., Crowley, P., Kohler, F.W. \& Strain, P.S. (1988) Redefinig the applied research agenda: Cooperative-learning, pre-referral teacher consultation, and peer mediated interventions, fournal of Learning Disabilities, 21(1), 43-52.

Maassen, G.H., Van der Linden, J.L., Goosens, F.A. \& Bokhorst, J. (2000) A ratingsbased approach to two-dimensional sociometric status determination, in: A.H. Cillessen \& W. Bukowski (Eds) Recent advances in the measurement of acceptance and rejection in the peer system (San Francisco, Jossey-Bass), 55-73.

Maassen, G.H. \& Verschueren, K. (2005) A two dimensional ratings-based procedure for sociometric status determination as an alternative to the Asher and Dodge System, Merrill-Palmer Quaterly, 51(3), 192-212.

Margolis, H. \& Freund, L.A. (1991) Implementing cooperative learning with mildly handicapped students in regular classrooms, International fournal of Disability, Development and Education, 31(2), 117-133.

Mascret, N. 2009. Les interactions 'joueur-coach' en badminton et leur impact sur les apprentissages en EPS des élèves difficiles [Player-coach interactions in badminton and their effects on the learning of failing students in PE], efRIEPS, 16, 55-72.

MEN (2002) Adaptation et intégration scolaires: des ressources au service d'une scolarité réussie pour tous les élèves [Adaptation and integration: Resources for a good scholarity for all students], Paris, Circulaire n ${ }^{\circ} 111$ du 30 avril 2002.

Michinov, E. (2001) L'attraction interpersonnelle Un concept en évolution [Interpersonal attraction: A changing concept], Les Cahiers Internationaux de Psychologie Sociale, 50, 11-26.

Ninot, G. \& Maiano, C. (2007) Long-term effects of athletics meet on the perceived competence of individuals with intellectual disabilities, Research in Developmental Disabilities, 28(3), 176-186.

Oden, S. \& Asher, S.R. (1977) Coaching children in social skills for friendship making, Child Development, 48(2), 495-506.

Parlebas, P. (1992) Sociométrie, réseaux et communication [Sociometry, networks and communication] (Paris, PUF).

Pasquier, J.L. (1999) L'intégration des ses/segpa dans les collèges en 1992 peut-elle nous éclairer au XXI siècle ? [Does SEGPAs integration light us at the twenty-first century] La nouvelle Revue de L'AIS, 8, 32-37.

Piercy, M., Wilton, K. \& Townsend, M. (2002) Promoting the social acceptance of young children with moderate-severe intellectual disabilities using cooperative techniques, American fournal of Mental Retardation, 107(5), 352-360.

Putnam, J.W. (1998) Cooperative learning and strategies for inclusion: Celebrating diversity in the classroom (Brookes, Baltimore).

Putnam, J., Markovchick, K., Johnson, D.W. \& Johnson, R.T. (1996) Cooperative learning and peer acceptance of students with learning disabilities, The fournal of Social Psychology, 136(6), 741-752. 
Putnam, J.W., Rynders, J.E., Johnson, R.T. \& Johnson, D.W. (1989) Collaborative skill for promoting interactions between mentally handicapped and non handicapped children, Exceptional Children, 55(6), 550-557.

Recours, R., Souville, M. \& Griffet, J. (2004) Expressed motives for informal and club/ association-based sport participation, fournal of Leisure Research, 36(1), 1-22.

Rubin, K.H., Bukowski, W.M. \& Parker, J.G. (1998) Peer interactions, relationships, and groups, in: W. Damon \& N. Eisenberg (Eds) Handbook of child psychology, Social, emotional, and personality development (Vol. 3) (New York, Wiley), 619-700.

Sabornie, E., Evans, E. \& Cullinan, C. (2006) Comparing characteristics of high-incidence disability groups, Remedial and Special Education, 27(2), 95-104.

Schwartz, I., Staub, D., Peck, C. \& Gallucci, C. (2006) Peer relationships, in: M. Snell \& F. Brown (Eds) Instruction of students with severe disabilities (Upper Saddle River, NJ, Pearson Prentice Hall).

Soulé, B. \& Corneloup, P. (2006) Sociologie du risque dans les pratiques sportives [Sociology of risk taking in sport] (Paris, Armand Colin).

Stainback, S. \& Stainback, W. (1992) Curriculum considerations in inclusive classrooms: Facilitating learning for all students (Baltimore, ML, Paul H. Brookes).

Zuckerman, M. (1990) The psychophysiology of sensation seeking, fournal of Personality, $4(1), 14-27$. 